\title{
Assessment of structure and selected mechanical properties of braze welded joints of copper-lined steel tubes
}

\author{
Zbigniew Mirski $^{1}$ (D) Tomasz Wojdat $^{1}$ (D) Jan Hejna ${ }^{2}$ D
}

Received: 21 January 2020 / Revised: 21 January 2020 / Accepted: 1 February 2020 / Published online: 17 February 2020

(c) The Author(s) 2020

\begin{abstract}
In the paper, results of a research on braze welded joints of copper-lined 10CrMo9-10 (10H2M) steel tubes made by CMT arc braze welding are presented. As a filler metal, silicon bronze was applied. Results of metallographic examinations with the use of light microscopy, electron scanning microscopy and X-ray microanalysis are presented. Mechanical properties of the joints were assessed on the grounds of static tensile test, technological bending test, as well as hardness measurements. Quality of the obtained joints was good. No cracks were observed in the brazed joints and the obtained mechanical properties were satisfactory.
\end{abstract}

Keywords 10CrMo9-10 steel · Cu-ETP copper $\cdot \mathrm{CuSi} 3$ filler metal $\cdot$ CMT braze welding $\cdot$ Braze weld $\cdot$ Reaction zone $\cdot$ Inclusions in braze weld $\cdot$ Metallographic examinations $\cdot$ Mechanical properties of joints

\section{Introduction}

Joining dissimilar materials is related to various difficulties that can basically affect quality of the obtained joints. In such a case, the main difficulties are of metallurgical nature and occur especially in the welding processes, where components of base materials and the filler metal are alloyed together, i.e. in the so-called fusion welding [1]. This may cause the formation of hard reaction zones [2] or hot cracks [3]. This problem occurs also during bonding copper with steel [4]. Joints of these materials are, nowadays, widely used in various industries, among others in cooling appliances, heating systems, boilers, household appliances, structures built for chemical, shipbuilding and metallurgical industries [5], as well as in windings of high-power generators [6].

In the case of joining copper with steel, the main problem results from limited solubility of copper in steel [7].

Tomasz Wojdat

tomasz.wojdat@pwr.edu.pl

1 Department of Metal Forming, Welding and Metrology, Faculty of Mechanical Engineering, Wroclaw University of Science and Technology, Wrocław, Poland

2 Department of Vehicle Engineering, Faculty of Mechanical Engineering, Wroclaw University of Science and Technology, Wrocław, Poland
Maximum solubility of copper at high temperature is 6.5 wt $\%$ in $\delta$ iron, $8 \mathrm{wt} \%$ in $\gamma$ iron and $1.4 \mathrm{wt} \%$ in $\alpha$ iron [8]. At ambient temperature, at phase equilibrium state (Fig. 1), solubility of copper in iron is limited to $0.3 \mathrm{wt} \%$ only [7].

This restricts application of traditional methods of arc welding, commonly used in industry, i.e. the methods MIG and TIG [9]. An alternative for them can be low-energy versions of GMA (Gas Metal Arc) welding: ColdArc, STT (Surface Tension Transfer), CMT (Cold Metal Transfer), etc. [10], with synergic lines dedicated for the brazing process [11]. The low-energy arc joining processes are dedicated for materials sensitive to heat [12] and joining thin sheets [13]. Application of braze welding significantly reduces the possibility of hot cracking, since, in this process, partial melting of the joined materials and mixing their components with the filler metal do not occur or are considerably reduced and the joint is obtained mainly by wetting and diffusion, like at brazing (less often at soft soldering) $[10,11]$. The way of preparing the materials for braze welding is identical to that applied in the welding process, i.e. with a gap or chamfered edges, with no capillary gap, characteristic for brazing [11]. 


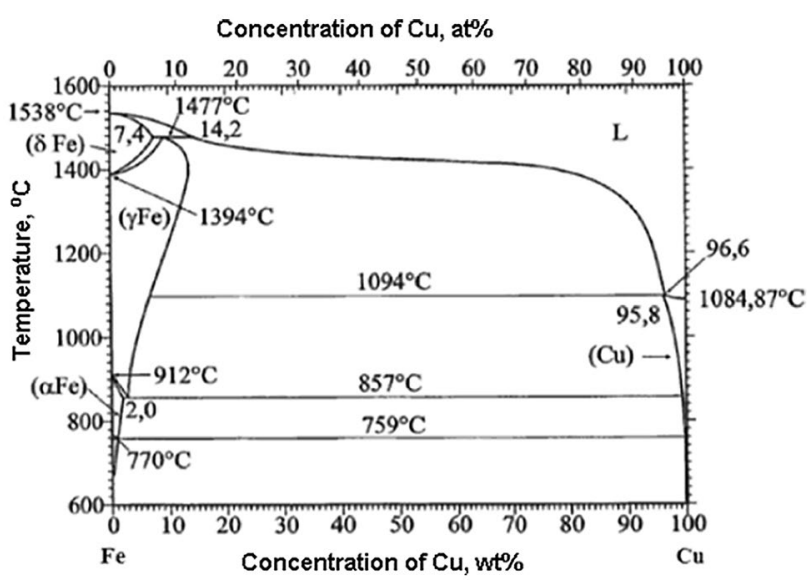

Fig. 1 Phase equilibrium diagram $\mathrm{Cu}-\mathrm{Fe}$ [7]

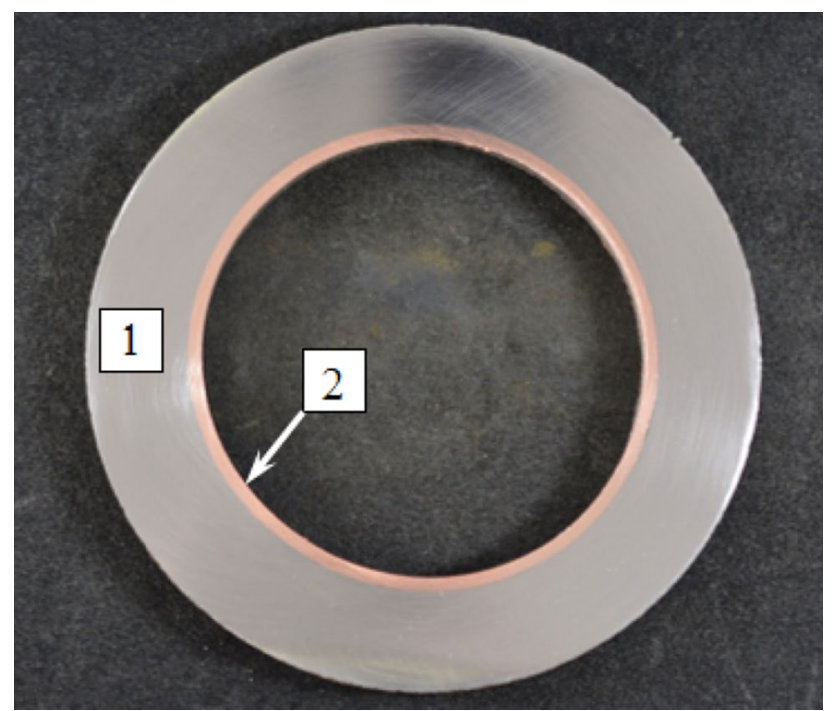

Fig. 2. $10 \mathrm{CrMo} 9-10$ steel tube (1) with internal Cu-ETP lining (2)

\section{Materials for braze welding}

The base material to be examined was a steel tube grade 10CrMo9-10 (1.7380) with outside diameter $101.6 \mathrm{~mm}$ and wall thickness $15.5 \mathrm{~mm}$, with internal copper lining 2-mm thick (Fig. 2). The tube is designed for application in the chemical industry at $550{ }^{\circ} \mathrm{C}$ and under pressure of 40 bar. The internal copper lining is mechanically forced to the steel tube and protects steel against corrosive action of aggressive working medium.

According to EN 10216-2:2014-02, the 10CrMo9-10 steel belongs to the group of steels designed for operation at elevated temperatures. It is mainly applied in manufacture of steam boilers, steam turbines, steam pipelines and pressure appliances. The Cu-ETP copper, of which the internal lining was made, is classified as "electrolytic tough pitch copper" with controlled low content of oxygen (copper oxide). It is characterised by very good thermal and electrical conductivity, good corrosion resistance in various environments and resistance to most aggressive media except those containing ammonia. It is widely used in electrical industry, in sanitary systems and in automotive industry.

Selection of a filler metal for braze welding dissimilar materials is a big problem. Generally, its melting point corresponds to that of the lower-melting base material $[10,11]$. If the difference between melting points of the filler metal and the base material is small, it is not always possible to avoid partial melting of the edge of the lower-melting material [14]. For brazing the 10CrMo9-10 steel tube with copper lining, the silicon bronze $\mathrm{CuSi} 3$ in the form of dia. $1.0-\mathrm{mm}$ wire was selected.

Chemical compositions of the medium-alloyed steel 10CrMo9-10 acc. to EN 10216-2:2014-02, Cu-ETP copper acc. to EN 13599:2014-04 and the filler metal CuSi3 acc. to EN ISO 24373:2009 are presented in Table 1.

Depending on cooling rate, different microstructures of the 10CrMo9-10 steel can be obtained: bainitic after air cooling (normalising), ferritic-bainitic after slow furnace cooling (annealing) and martensitic after quenching in oil. Bainite obtained in this steel is globular (carbide free) and is subjected to tempering, like martensite.

Microstructure of the examined steel 10CrMo9-10 is ferritic-bainitic with diversified ferrite grain size and with slight banding (Fig. 3).

\section{Fabrication of braze welded joints}

Preparation of the tube for braze welding by "V" chamfering its edges is shown in Fig. 4.

Table 1 Chemical compositions of joined materials and filler metal

\begin{tabular}{|c|c|c|c|c|c|c|c|c|c|c|c|c|c|c|c|}
\hline \multirow[t]{2}{*}{ Material } & \multicolumn{15}{|c|}{ Chemical composition (wt\%) } \\
\hline & $\mathrm{C}$ & Mo & $\mathrm{Si}$ & $\mathrm{Mn}$ & $\mathrm{Cr}$ & $\mathrm{Ni}$ & $\mathrm{P}$ & $\mathrm{S}$ & Sn & $\mathrm{Zn}$ & B & $\mathrm{O}$ & $\mathrm{Pb}$ & $\mathrm{Cu}$ & $\mathrm{Fe}$ \\
\hline 10CrMo9-10 & $0.08 \div 0.15$ & $0.9 \div 1.1$ & $0.15 \div 0.50$ & $0.4 \div 0.6$ & $2.0 \div 2.5$ & & $<0.03$ & $<0.03$ & - & - & - & - & & $<0.25$ & Rem \\
\hline Cu-ETP & - & - & - & - & - & $<0.3$ & - & - & - & - & 0.0005 & 0.04 & 0.005 & Rem & - \\
\hline $\mathrm{CuSi} 3$ & - & - & $<3.0$ & $<1.0$ & - & - & - & - & $<0.1$ & $<0.1$ & - & - & - & 0.07 & Rem \\
\hline
\end{tabular}




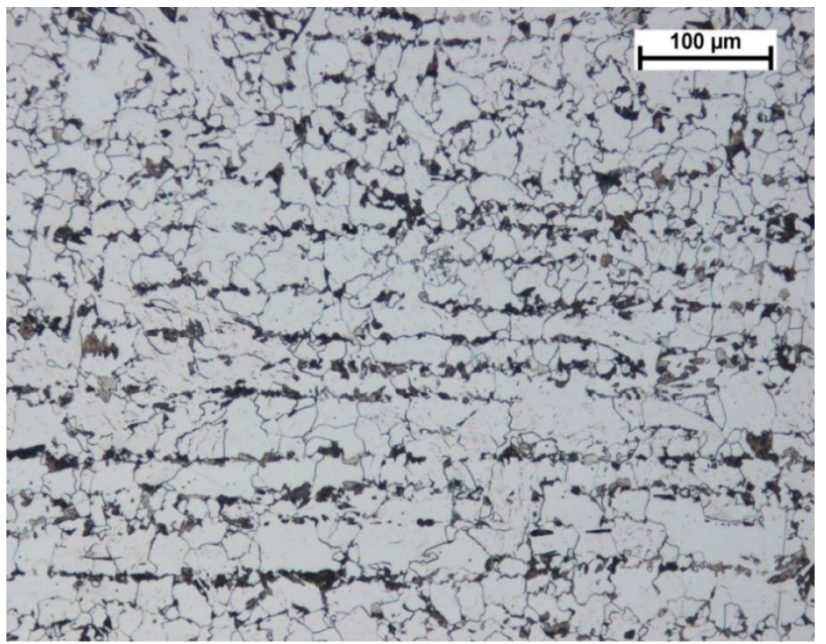

Fig. 3 Ferritic-bainitic microstructure of 10CrMo9-10 steel. Etched with Nital

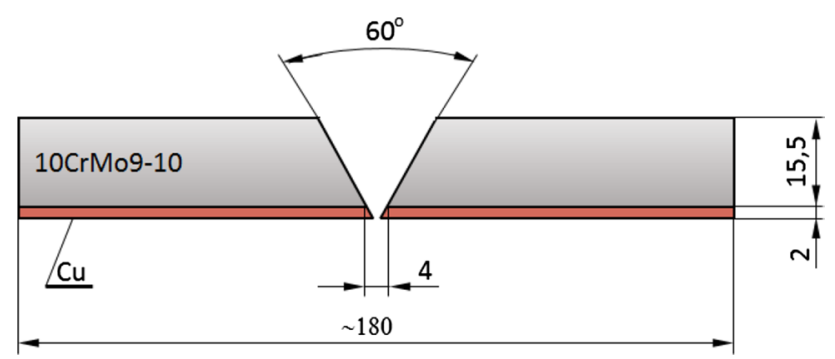

Fig. 4 Preparation of copper-lined 10CrMo9-10 tube for braze welding

With regard to small quantity of the material (steel tube with copper lining) and results of the first braze welding trials, the tubes were not joined on their entire circumference, but were cut lengthwise into 4 equal pieces-quarters, each 90-mm long. Before braze welding, thin copper plates-runon and run-off ones-were TIG-welded to the tube quarters (Fig. 5). The TIG welds were made only between the inner copper pipe and the copper plates. This was done with the introduction of the minimum welding linear energy and was necessary for the experiment, in which only a quarter of the circumference of the pipe was braze welding. Under normal braze welding conditions, this type of pipeline is not necessary.

The braze welding process was carried out on a robotized station, using the low-energy method CMT, under shielding of pure argon 4.5 (99.995 vol\% Ar).

The station was equipped with a synergic power source Fronius TransPuls Synergic 3200 with a digital control of welding current, a system responsible for wire withdrawal at the moment of a short circuit to minimise spattering and a digitally controlled wire feeder Fronius VR 7000-CMT

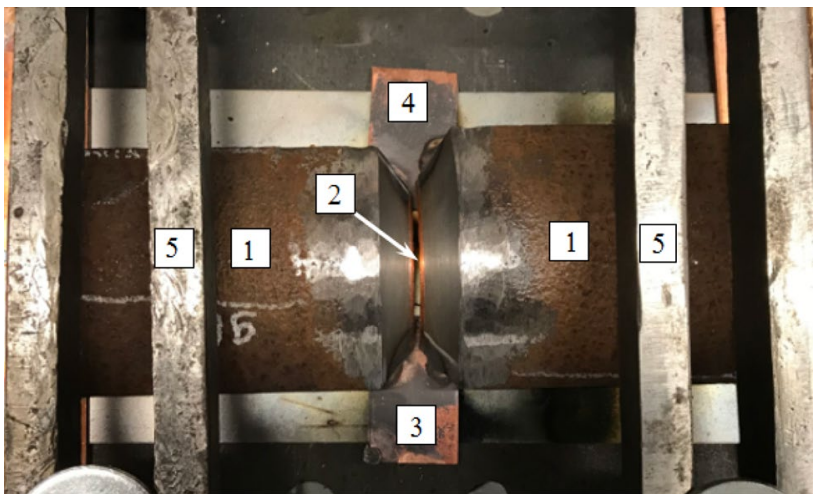

Fig. 5 Preparation of specimens for braze welding: $1-10 \mathrm{CrMo} 9-10$ steel tubes, 2- $\mathrm{Cu}$ lining, 3-run-on plate, 4-run-off plate, 5-fixing holders

4R/G/W/F++. Working movements during the process were executed by the robot Kawasaki series BA with a welding clamp Robacta Drive CMT PAPW fitted on its arm end, with an integrated, numerically controlled, asynchronous $\mathrm{AC}$ motor permitting quick withdrawal of wire to the special buffer [15].

The braze welding parameters were selected on copper plates of $2.0-\mathrm{mm}$ thick. It was started from the parameters implemented in the synergic line for the filler metal $\mathrm{CuSi} 3$ and copper as the base material with a preset thickness. Next, these parameters were corrected by changing the braze welding speed. The preliminary trials demonstrated that the process requires a very precise selection of process parameters, whose change — even within a very narrow range—decreases the process stability and results in numerous imperfections in the joints. Even small changes of parameters resulted in, e.g. spattering due to lower process stability, lack of wetting and bonding or excessive partial melting (melt-through) of copper edges. Final parameters of CMT braze welding, for which two joints (Nos. 1 and 2) were made, are shown in Table 2 . The welding groove was completely filled by application of 15 seams. After execution of trial joints, the run-on and run-off plates were removed and then specimens for metallographic macro- and microscopic examinations and for mechanical testing were cut out.

\section{Radiographic examinations}

Radiographic testing (RT) was carried out according to the standards EN ISO 17636-1:2013-06 and EN 12799:2003/ A1:2005. The radiographs executed on $1 / 4$ circumference of tubular joints did not show any internal imperfections in the braze welded joints. An exemplary radiograph is shown in Fig. 6. 
Table 2 Parameters of braze welding copper-lined tube of 10CrMo910 steel

\begin{tabular}{lll}
\hline Item & Parameter & Value \\
\hline 1 & Current intensity, $I S$ & $178 \mathrm{~A}$ \\
2 & Arc voltage, $U$ & $18 \mathrm{~V}$ \\
3 & Wire feeding rate, $V d$ & $10.8 \mathrm{~m} / \mathrm{min}$ \\
4 & Braze welding speed, $V s$ & $60 \mathrm{~cm} / \mathrm{min}$ \\
5 & Wire extension, $L w$ & $15 \mathrm{~mm}$ \\
6 & Argon flow rate, $Q$ & $16 \mathrm{~m}^{3} / \mathrm{min}$ \\
\hline
\end{tabular}

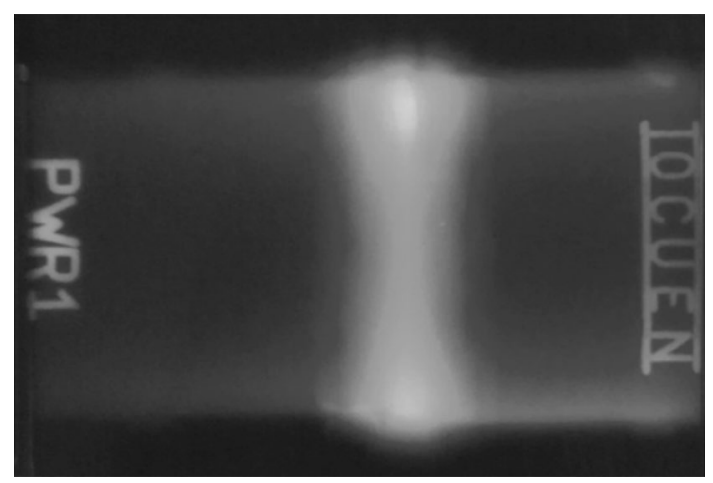

Fig. 6 Exemplary radiograph (negative) of a braze welded joint of copper-lined 10CrMo9-10 steel tube

\section{Macroscopic examinations}

Polished sections for macro- and microscopic examinations were prepared in a standard way. The specimens were ground on abrasive papers and next polished using diamond pastes. Macroscopic examinations were performed with an unaided eye and with use of a stereoscopic microscope MST-800 Nikon.

It can be seen in Fig. 7 that the joint was made in a correct way, with no visible macroscopic imperfections. A missing connection between the steel tube (1) and the copper lining (2) on the whole length of the tube (which results from mechanical assembly of steel tube and lining by forcing in) is visible. However, the connection exists in the braze welded place. A small partial melting can be seen at the weld root and at the weld face (A, B). Braze welded joints are assessed like brazed joints; so according to EN ISO 18279:2008, this is an imperfection 7UAAC of the group VI "Miscellaneous imperfections", i.e. the excessive reaction of the filler metal with the base material. In dissimilar joints, especially of steel and copper, it can be important, which of the materials undergoes partial melting. Chemical composition of the filler metal is similar to that of the copper lining; so it is more favourable that copper is partially melted. In the case when partial melting

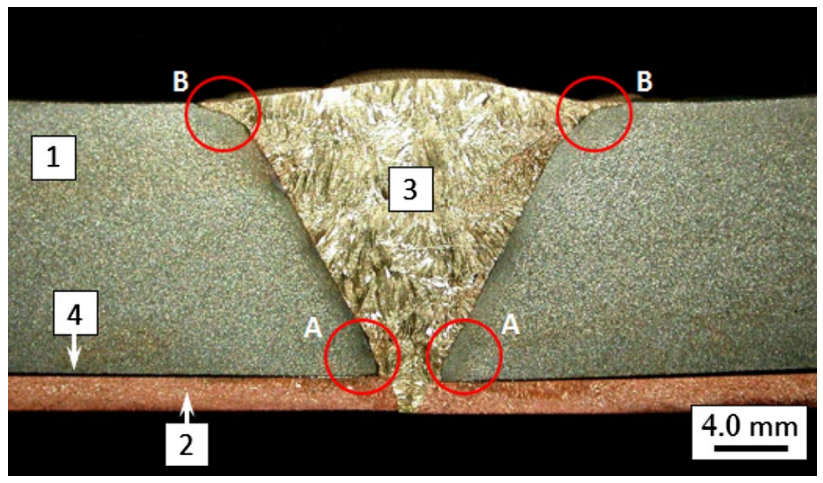

Fig. 7 Macrostructure of braze welded joint No. 1: 10CrMo9-10 steel tube (1), copper lining (2), braze weld (3), missing connection between steel and copper lining (4), partial melting of steel (A, B). Etched chemically with Nital and with a solution of chromic and nitric acids

of steel occurs, hot cracks can emerge as a result of copper diffusion from the filler metal to the steel along grain boundaries, which was presented in [16]. Formation of hot cracks could be also favoured by quick dissipation of heat from the joint area by the copper lining, which increases tensile stresses in the steel and facilitates diffusion of copper from the deposited metal along grain boundaries. In the considered case, no macroscopic hot cracks were found in steel.

\section{Microscopic examinations and EDS microanalysis}

Microscopic examinations were carried out using a light microscope Olympus $\mathrm{C} 40 \mathrm{M}$ with image recording by a digital CCD camera.

For the examinations, two braze welded joints Nos. 1 and 2 were chosen. Observations were performed in various areas of the weld and the joined materials. Since they are braze welded joints created by diffusive mechanisms, their functionality and mechanical properties depend, to a high degree, on quality of the connection of the boundary between the braze weld and the 10CrMo9-10 steel. In the central part of the joint No. 1, both on the left and on the right of the weld, a reaction zone with variable width is visible, created as a result of a dissolution of the steel into the braze weld as well as partial melting of steel (Fig. 8).

The reaction zone on the left side of the weld (Fig. 8a) is ca. 4 times wider $(10 \div 15 \mu \mathrm{m})$ than on the opposite side (Fig. 8b). It was caused by position of the welding clamp (from that the electrode wire was advanced) in relation to the edge of the welding groove and/or the sequence of applying individual seams. The first seam was applied on the right side, so—when applying the seam on the left side—-the base 
Fig. 8 Microstructure of brazed joint No. 1: 10CrMo9-10 steel tube (1), braze weld (2), reaction zone (3), inclusions in the weld (4). Left side of the (b). Etched chemically with Nital and with $10 \%$ solution of ammonium persulphate weld (a); right side of the weld
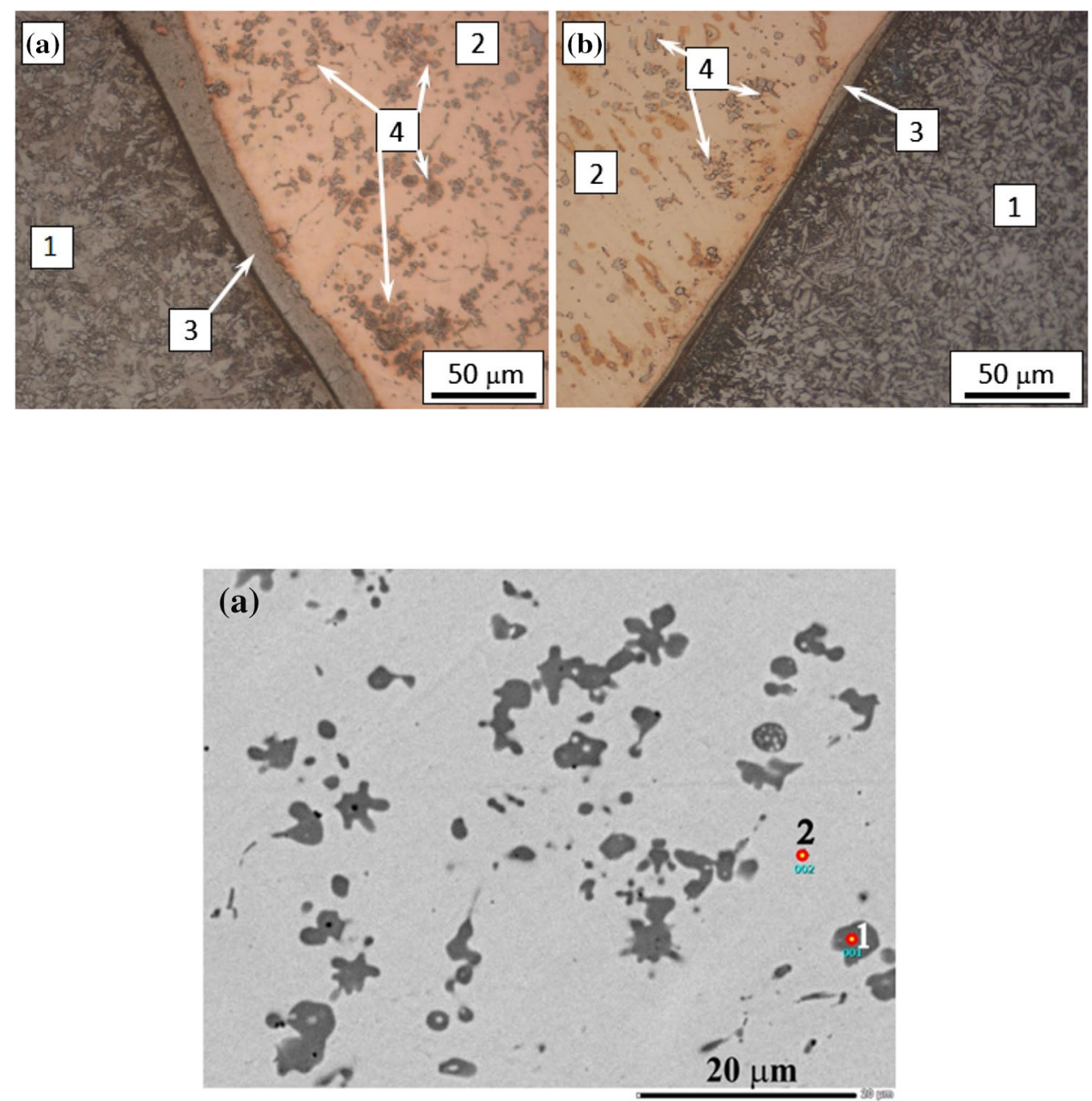

Fig. 9 Microstructure of brazed joint (a) with inclusions from Fig. 8a (material contrast) and characteristic X-ray spectra for the inclusion (b) and the matrix (c). Primary beam energy $E_{0}=20 \mathrm{keV}$
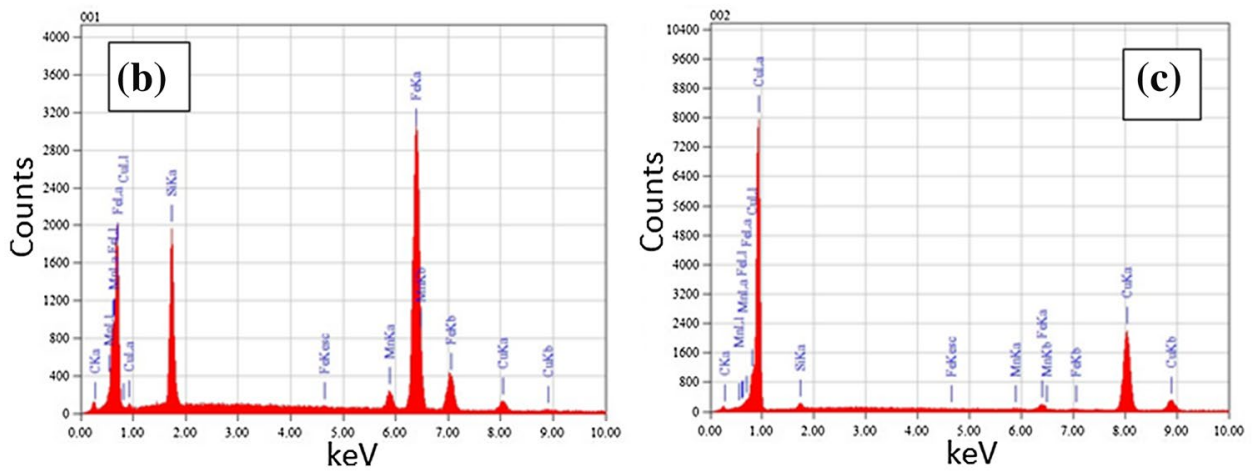

material was heated to a higher temperature, which is conducive for the diffusion mechanisms responsible for creation of the reaction zone. A slight partial melting of steel could also take place. Tiny inclusions are present in the braze weld, whose larger amount can be also observed on the left side of the joint - with wider reaction zone.

SEM examinations and EDS microanalysis were carried out using a scanning electron microscope JEOL JSM6610 equipped with an EDS spectrometer. Local qualitative and quantitative analyses were also performed using a standardless programme ZAF, and element distribution maps were recorded.

Inclusions in the braze weld were identified as an intermetallic phase, rich in Fe and Si (Fig. 9 and Table 3). Tiny inclusions created by precipitating from a liquid filler material in which Fe coming from partially melted steel has been dissolved.

From the Si side of the Fe-Si system (Fig. 10a) [17], 3 silicon solutions in iron occur: disordered solution $\alpha$ (marked as $\alpha \mathrm{Fe}$ in the diagram) up to 10 at.\% Si at ambient 
Table 3 Results of local quantitative analysis for the braze weld from Fig. 9a

\begin{tabular}{lllllll}
\hline Point no & Location & $\%$ & & Element & & \\
\cline { 3 - 6 } & & & $\mathrm{Cu}$ & $\mathrm{Fe}$ & $\mathrm{Si}$ & $\mathrm{Mn}$ \\
\hline 1 & Inclusion & wt\% & 5.2 & 77.6 & 14.4 & 2.9 \\
& & at.\% & 4.00 & 68.2 & 25.2 & 2.6 \\
2 & Matrix & wt\% & 95.5 & 2.7 & 2.7 & 0.4 \\
& & at.\% & 93.5 & 3.0 & 3.0 & 0.4 \\
\hline
\end{tabular}

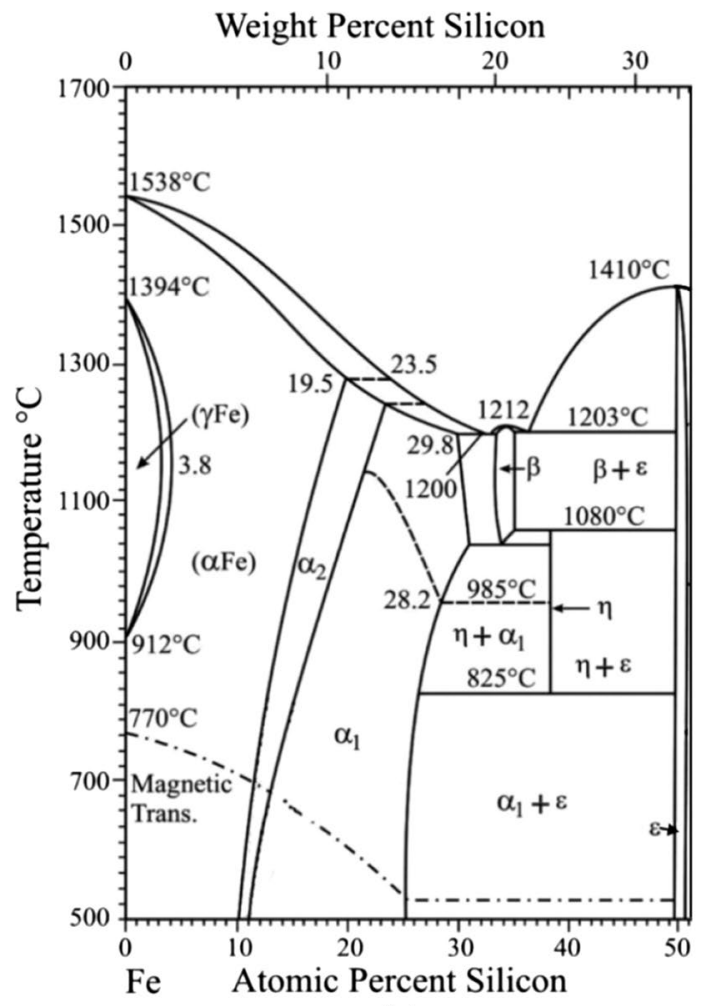

(a)

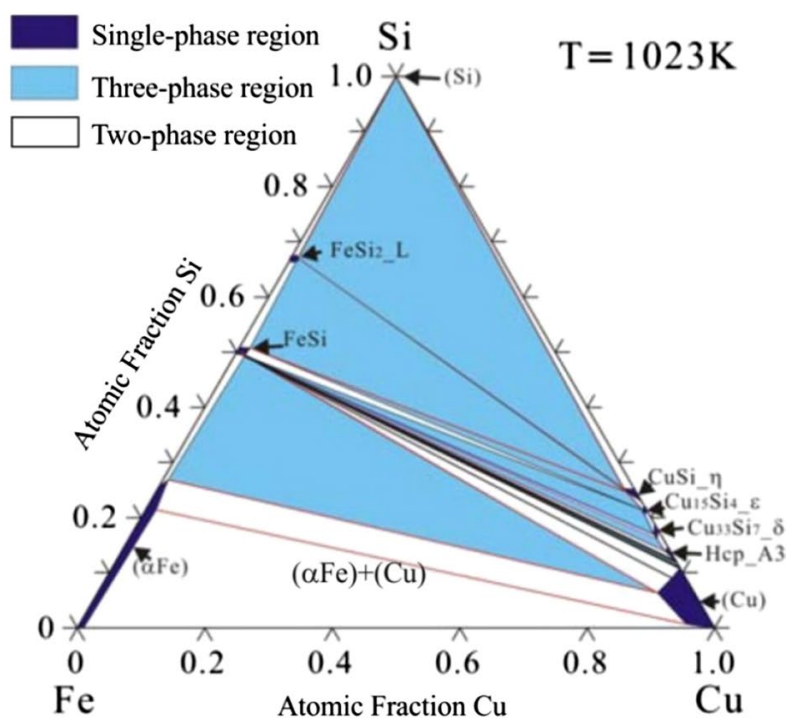

(b)

Fig. 10 A fragment of the phase equilibrium diagram $\mathrm{Fe}-\mathrm{Si}$ [17] (a) and isothermal section through the diagram for the system $\mathrm{Fe}-\mathrm{Cu}-\mathrm{Si}$ [19] (b)

temperature, ordered solution $\alpha_{2}$ within 10 and $11 \% \mathrm{Si}$ and ordered solution $\alpha_{1}$ within 11 and $25 \% \mathrm{Si}$. The ordered solutions are treated as intermetallic phases. The crystal lattice network B2 is attributed to the phase $\alpha_{2}$ and the lattice $\mathrm{D} 0_{3}$ is attributed to the phase $\alpha_{1}$ [18]. In the braze weld, the three-component system $\mathrm{Fe}-\mathrm{Si}-\mathrm{Cu}$ is present. Silicon only shows good solubility in iron, but solubilities of $\mathrm{Si}$ in $\mathrm{Cu}, \mathrm{Cu}$ in $\mathrm{Fe}$ and $\mathrm{Fe}$ in $\mathrm{Cu}$ are limited and, in the $\mathrm{Fe}-\mathrm{Si}-\mathrm{Cu}$ system, two- or three-phase mixtures are mostly present (Fig. 10b) [19]. Figure 10b shows an isothermal cross section of the phase equilibrium diagram $\mathrm{Fe}-\mathrm{Si}-\mathrm{Cu}$ at $750{ }^{\circ} \mathrm{C}$, but it can be supposed that differences of phase constitution at ambient temperature will not be large. In the braze weld and in the reaction zone, mixtures of various solutions of $\mathrm{Si}$ in $\mathrm{Fe}$ (marked as $\alpha \mathrm{Fe}$ in Fig. 10b), as well as solutions of Fe and $\mathrm{Si}$ in $\mathrm{Cu}$ (marked as $\mathrm{Cu}$ in Fig. 10b) can be expected. Table 3 shows results of EDS quantitative microanalysis of the braze weld in its central part. The structure is composed of the matrix being a solution of $\mathrm{Fe}$ and $\mathrm{Si}$ in $\mathrm{Cu}$ and particles of the phase $\alpha_{1}$. Analysis of the inclusions shows also the presence of $\mathrm{Cu}$, which can indicate that the particles are not one-phase, but, in addition to the $\alpha_{1}$ phase, they contain very tiny particles of a Cu-based solution. The braze weld contains also manganese coming from the filler metal and from steel. This element is mostly concentrated in the excluded particles. Manganese should not significantly affect properties of the braze weld. 
Fig. 11 Microstructure of braze welded joint No. 2: 10CrMo9-

10 steel tube (1), braze weld (2), reaction zone (3), inclusions in the braze weld (4). Left side of the weld in the central part (a), right side of the weld in the central part (b), left side of the weld at the root (c), right side of the weld at the root (d). Etched chemically with Nital and with $10 \%$ solution of ammonium persulphate
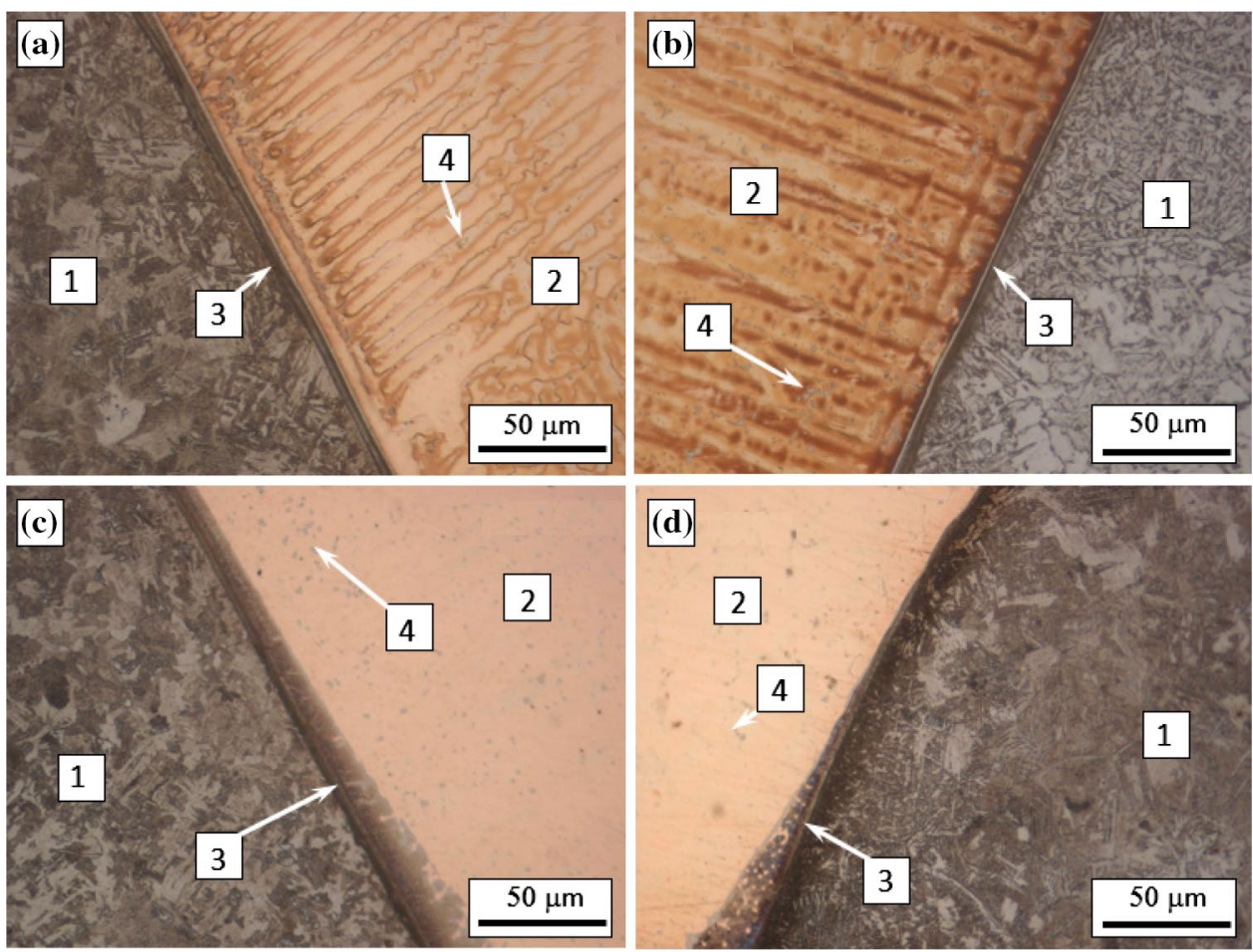

In the central part of the joint No. 2, on the boundary between steel and the braze weld, width of the reaction zone is comparable on both sides (Fig. 11a, b). In the braze weld itself, much smaller amount of the Fe-containing phase can be observed, which evidences much lower degree of its partial melting in this weld zone. Further in the direction of the weld root (Fig. 11c, d), width of the reaction zone clearly increases and quantity of $\alpha_{1}$ phase, containing mostly Fe and $\mathrm{Si}$, also increases. Width of the reaction zone is similar on both sides of the joint, slightly above $20 \mu \mathrm{m}$ just at the lower edge of the steel sheet.

Figure 12 shows microstructure of the braze weld reaction zone and its surroundings from Fig. 11a, with use of the contrast material from the place where the reaction zone is ca. $18-\mu \mathrm{m}$ thick. Table 4 shows results of quantitative microanalysis for the reaction zone and its surroundings in the braze weld from Fig. 12. It can be concluded on the grounds of these and the previous (Table 3) results that steel undergoes slight partial melting and creates with the liquid filler metal a non-homogenous liquid solution with high Fe concentration in vicinity of steel, and Si from the filler metal diffuses to the zone rich in Fe. When the joint is cooled down, various mixtures of the solutions $\mathrm{Fe}(\mathrm{Si})$ and $\mathrm{Cu}(\mathrm{Fe}, \mathrm{Si})$ are created in the braze weld.

It can be stated on the grounds of EDS microanalysis that the reaction zone is composed of the matrix rich in $\mathrm{Fe}$ and $\mathrm{Si}$ (dark phase) and particles of the phase rich in $\mathrm{Cu}$ (bright

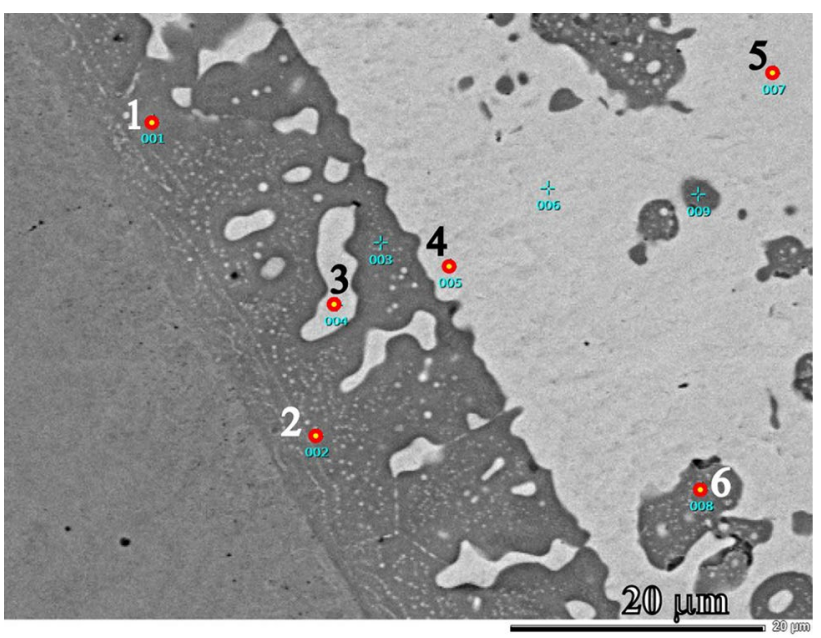

Fig. 12 Microstructure of the braze weld reaction zone and its surroundings from Fig. 11a. SEM (material contrast). Points of EDS analysis are marked. Primary beam energy $E_{0}=20 \mathrm{keV}$

phase); its small particles occur on the entire width of the reaction zone and big particles-on the weld side. Results of microanalysis of the phase rich in Fe and $\mathrm{Si}$ in the reaction zone are disturbed by tiny particles of the phase rich in $\mathrm{Cu}$. Concentration of copper is overstated in relation to the other elements. It can be supposed that, in the zone, the 
Table 4 Results of quantitative microanalysis for reaction zone and braze weld from Fig. 12

\begin{tabular}{|c|c|c|c|c|c|c|}
\hline \multirow[t]{2}{*}{ Point No } & \multirow[t]{2}{*}{ Location } & \multirow[t]{2}{*}{$\%$} & \multicolumn{4}{|c|}{ Element } \\
\hline & & & $\mathrm{Cu}$ & $\mathrm{Fe}$ & $\mathrm{Si}$ & $\mathrm{Mn}$ \\
\hline \multirow[t]{2}{*}{1} & \multirow[t]{2}{*}{ Reaction zone, dark phase } & wt $\%$ & 15.1 & 79.1 & 5.8 & - \\
\hline & & at. $\%$ & 12.7 & 76.1 & 11.1 & - \\
\hline \multirow[t]{2}{*}{2} & \multirow[t]{2}{*}{ Reaction zone, dark phase } & wt $\%$ & 7.0 & 87.1 & 5.9 & - \\
\hline & & at. $\%$ & 5.9 & 82.9 & 11.2 & - \\
\hline \multirow[t]{2}{*}{3} & \multirow[t]{2}{*}{ Reaction zone, bright phase } & $\mathrm{wt} \%$ & 89.9 & 8.8 & 0.7 & 0.7 \\
\hline & & at. $\%$ & 88.0 & 9.8 & 1.5 & 0.7 \\
\hline \multirow[t]{2}{*}{4} & \multirow[t]{2}{*}{ Braze weld, bright phase } & $\mathrm{wt} \%$ & 93.3 & 5.0 & 1.0 & - \\
\hline & & at. $\%$ & 91.4 & 5.6 & 2.2 & - \\
\hline \multirow[t]{2}{*}{5} & \multirow[t]{2}{*}{ Braze weld, bright phase } & $\mathrm{wt} \%$ & 94.5 & 3.6 & 1.1 & 0.8 \\
\hline & & at. $\%$ & 92.6 & 4.0 & 2.5 & 0.9 \\
\hline \multirow[t]{2}{*}{6} & \multirow[t]{2}{*}{ Braze weld, dark phase } & $\mathrm{wt} \%$ & 7.3 & 84.3 & 8.3 & - \\
\hline & & at. $\%$ & 6.0 & 78.6 & 15.4 & - \\
\hline
\end{tabular}

Figure 13 shows linear distribution of elements in the

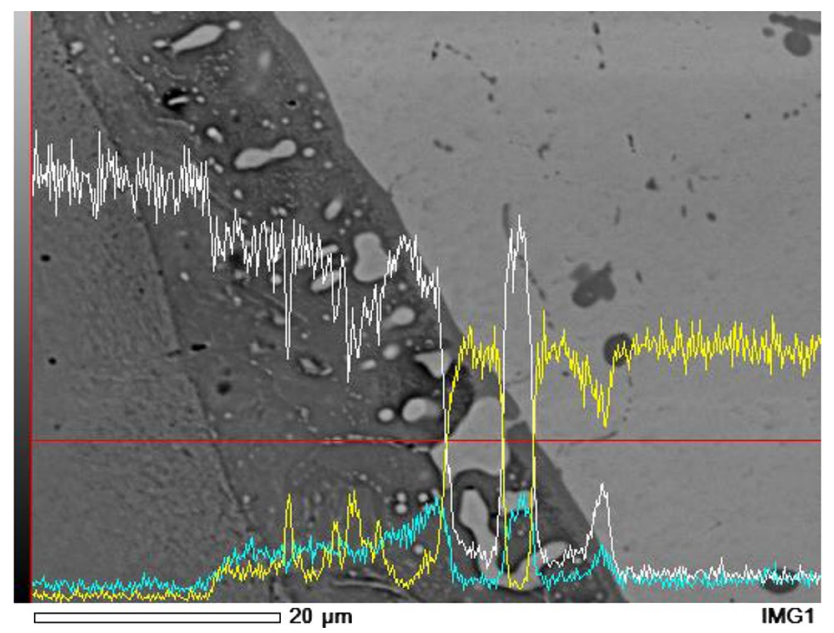
reaction zone and its surroundings from Fig. 11c, in the place where the reaction zone is $16-24-\mu \mathrm{m}$ thick. Like in the previous location, the zone contains $\mathrm{Cu}$-rich particles-tiny on the entire surface and large on the braze weld side. Quantitative analysis for the specimen from Fig. 13 indicates that concentration of silicon in the reaction zone increases towards the braze weld, reaching over 17 at.\% near the zone, i.e. 2 times more than near the steel. Compositions of the $\mathrm{Cu}$-rich precipitate and of the braze weld are similar like in the previous location. Concentration of $\mathrm{Si}$ in the reaction zone reaches ca. 25 at.\%, i.e. the upper limit for the phase $\alpha_{1}$. An increase of Si concentration in the reaction zone towards the braze weld is also visible in Fig. 14 showing distribution maps of the elements.

\section{Mechanical testing of braze welded joints} roundings from Fig. 11c. SEM (material contrast). Linear distribution of elements along the red line: $\mathrm{Fe}-$ white line, $\mathrm{Cu}-$ yellow line, $\mathrm{Si}-$ blue line

intermetallic phase $\alpha_{1}$ (or $\alpha_{2}$-concentration of $\mathrm{Si}$ is close to the limit between both phases) is present, containing precipitates of the solution of $\mathrm{Fe}, \mathrm{Si}$ and $\mathrm{Mn}$ in $\mathrm{Cu}$ (ca. $90 \mathrm{wt} \% \mathrm{Cu}$ ). Manganese occurs mainly in the precipitates; its concentration in the phase $\alpha_{1}$ is below the spectrometer detectability. The braze weld is composed of the matrix being a solution of $\mathrm{Fe}, \mathrm{Si}$ and $\mathrm{Mn}$ in $\mathrm{Cu}$ and particles rich in $\mathrm{Fe}$ and $\mathrm{Si}$; some of them contain tiny precipitates of the phase rich in $\mathrm{Cu}$. Concentration of copper was found higher in the braze weld than in the reaction zone. The precipitates in the braze weld contain over 15 at. $\% \mathrm{Si}$, which indicates the phase $\alpha_{1}$.
Specimens for the static tensile test were prepared according to EN ISO 4136:2013-05 and EN 12797:2002/A1:2005. From the braze welded joints, specimens 20 -mm wide were cut out, and then milled to $12 \mathrm{~mm}$ in the gauge length. Tensile tests of the braze welded joints were carried out on a hydraulic universal testing machine. The measuring range was up to $40 \mathrm{kN}$ and travelling speed of the traverse was $2 \mathrm{~mm} / \mathrm{min}$. Average tensile strength of the braze welded joints was 204.5 MPa (average from 2 tests, because of limited quantity of the tested material). The fracture mechanism was cohesive, since the specimens were failed within the braze weld or partially within the braze weld and the reaction zone (Fig. 15). 

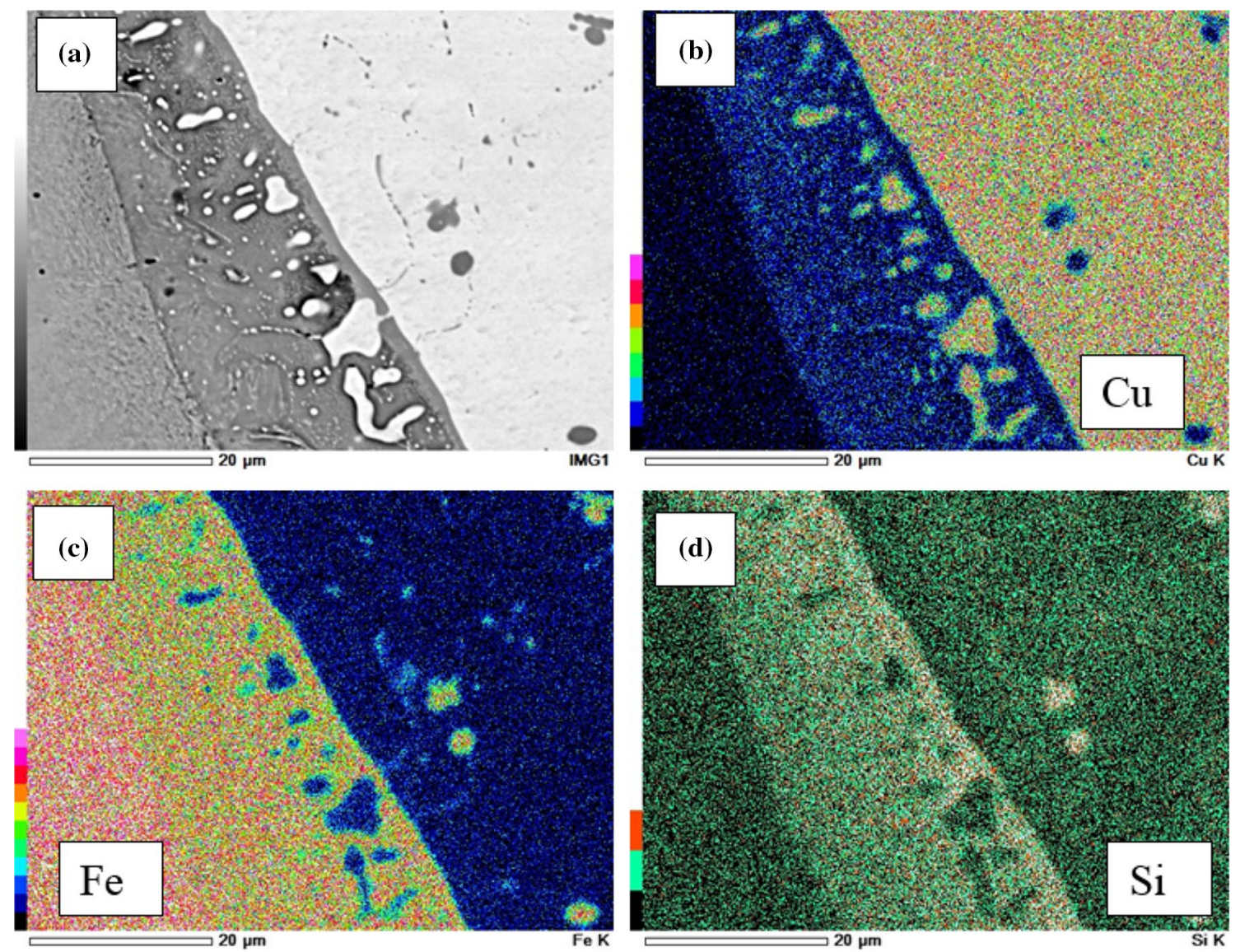

Fig. 14 SEM image from Fig. 13 (a) and distribution maps of $\mathrm{Cu}(\mathbf{b}), \mathrm{Fe}(\mathbf{c})$ and $\mathrm{Si}(\mathbf{d})$ on surface of the braze welded joint

The obtained results are much better than those obtained for the same type joints made by flame $\left(\mathrm{C}_{2} \mathrm{H}_{2}-\mathrm{O}_{2}\right)$ braze welding with the use of coated brass filler wire grade 18XFC [15], as shown in Fig. 16. Tensile strength of the flame brazed joints was in average $145 \mathrm{MPa}$ (in the range of $139 \div 150 \mathrm{MPa}$ ) and the fracture mechanism was adhesivethe braze weld was torn-off from the 10CrMo9-10 steel on side surface of the chamfered tube groove.

Results of the technological bending test are also significantly diversified and indicate that, in the considered application case, better results can be obtained by the arcbrazing CMT technology (Fig. 17). The bending tests were continued to the moment when the first cracks appeared in the joint or in its vicinity. In the case of the CMT brazed joints, the bending angle was over 4 times bigger, equal to $45^{\circ}$, which is a very good result, taking into account significant thickness of the joined elements and the applied CMT brazing technology.

Vickers hardness measurements in the braze welded joint of $\mathrm{Cu}$-lined 10CrMo9-10 steel tube were made acc. to EN ISO 6507-1:2007, using a tester Zwick 321 under the indenter load of $10 \mathrm{kG}(98.07 \mathrm{~N})$ for $15 \mathrm{~s}$. Hardness of the base material (steel 10CrMo9-10) ranged within 157-168
HV 10 and hardness in the heat-affected zone was 181 HV 10. The braze weld created of the filler metal $\mathrm{CuSi} 3$ is soft; its hardness is ranging within 86-92 HV 10. In addition, hardness at $50 \mathrm{G}$ load was measured in the reaction zone due to its small width. The reaction zone is the hardest place in the brazed joint, with its hardness equal to 491.1 HV 0.05. The softest zone is matrix of the braze weld CuSi3, with its hardness equal to $134.6 \mathrm{HV}$ 0.05, see Fig. 18.

\section{Conclusions}

Bonding copper with steel is not an easy process and is problematic in the case of welding, where, as a result of significant mixing of copper with steel, hot cracks occur. Application of the low-energy CMT method for braze welding of boiler 10CrMo9-10 steel lined with copper makes it possible to obtain joints with good quality, highly aesthetic and with no spattering. Even if the braze welding process was applied, intensive diffusion processes proceeded and slight partial melting of the base material (10CrMo9-10 steel) occurred, especially in the weld face and root areas. As a result, a ca. $24-\mu \mathrm{m}$-wide reaction zone at the boundary between steel 

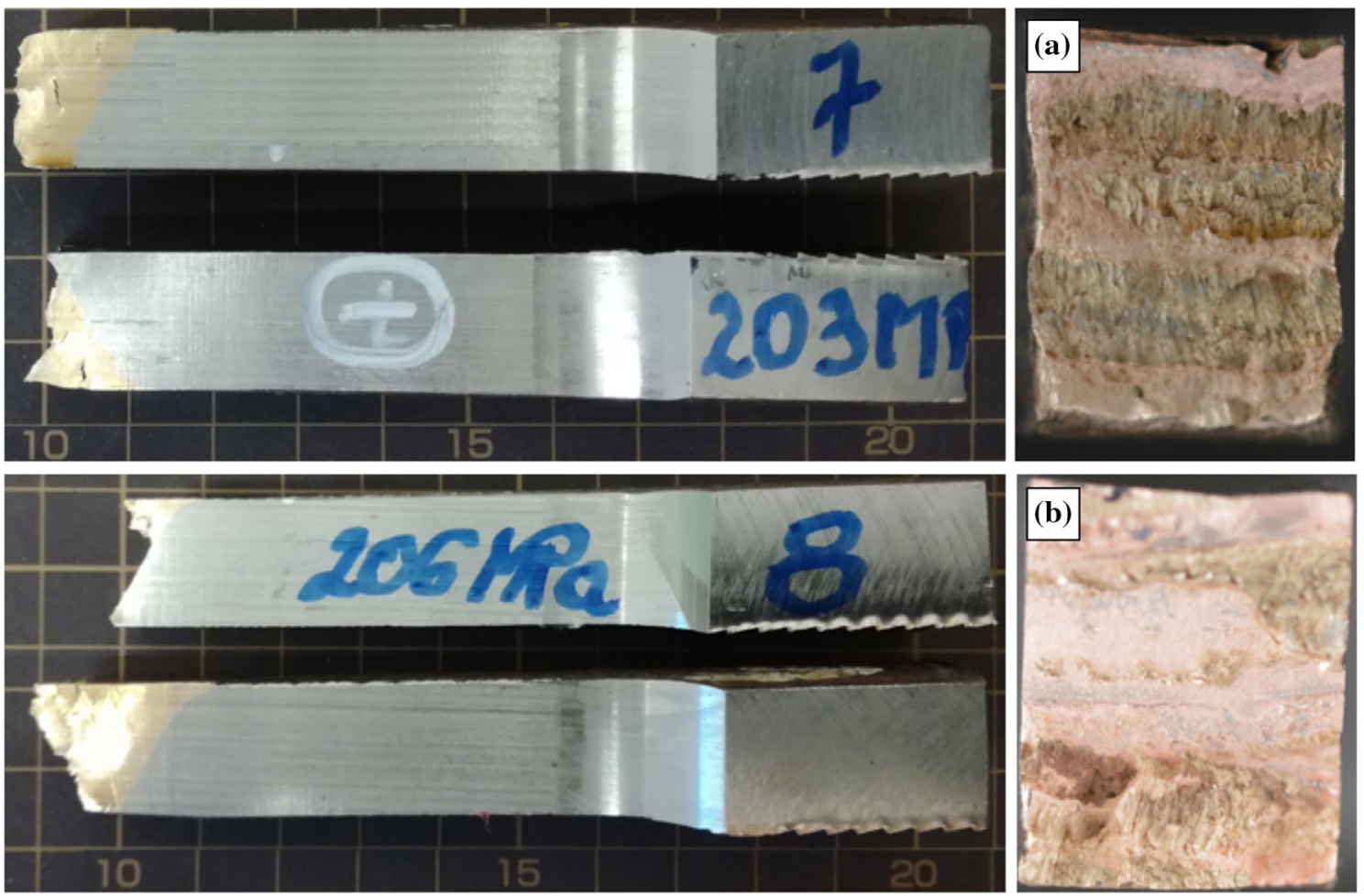

Fig. 15 Exemplary fractures of the joints after tensile test: cohesive fracture in the braze weld (a) and cohesive fracture in the braze weld and in the reaction zone $(\mathbf{b})$
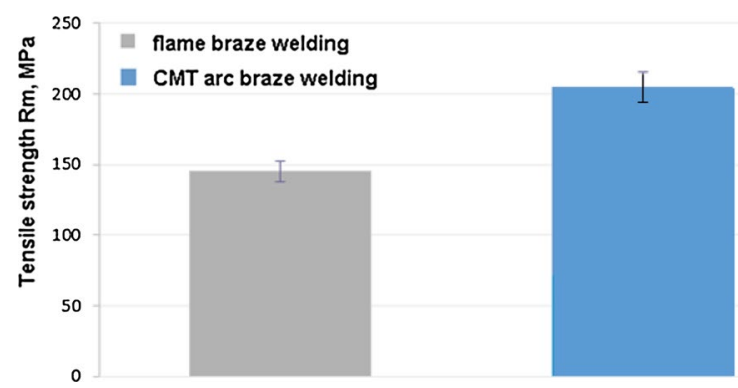

Fig. 16 Tensile strength of braze welded joints of copper-lined 10CrMo9-10 tube

and the braze weld was created. The reaction zone consists mostly of phase $\alpha_{1}$ being the ordered solution $\mathrm{Fe}_{\alpha}(\mathrm{Si})$. This is a hard and brittle phase showing the highest hardness in the braze weld (491.1 HV 0.05); however, no cracks were observed in this phase. Tiny precipitates of $\alpha_{1}$ phase occur in the braze weld, but they can not significantly affect properties of the joint. Mechanical properties of CMT arc braze welded joints are good and much higher than those of the same type flame braze welded joints. Tensile strength of the joints is $204.5 \mathrm{MPa}$ and the cohesive fracture is located within the soft braze weld. Application of the CMT arc braze

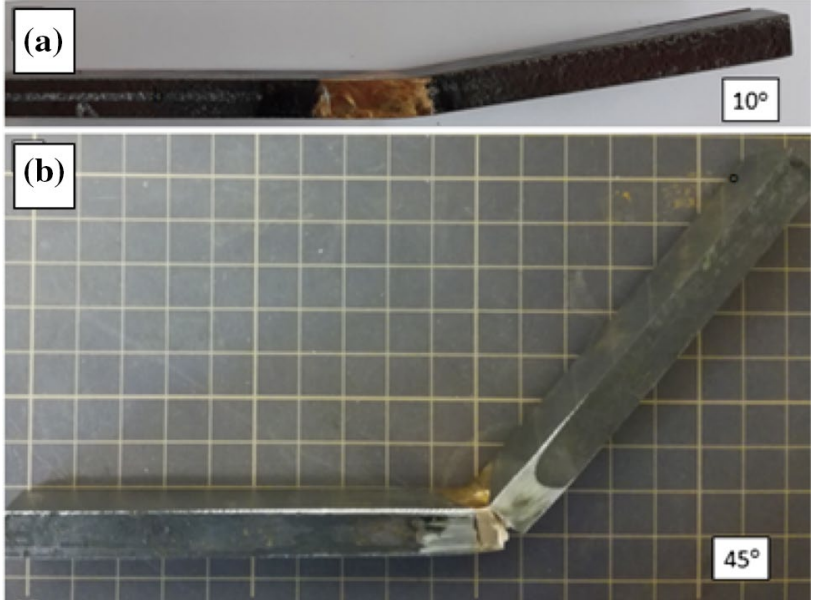

Fig. 17 Joints of $\mathrm{Cu}$-lined 10CrMo9-10 tube after technological bending test: flame braze welded (a) and CMT arc-braze welded (b)

welding technology eliminates or highly restricts the risk of hot cracking, both in steel as a result of copper diffusion from the filler metal along grain boundaries, and in the braze weld itself. 


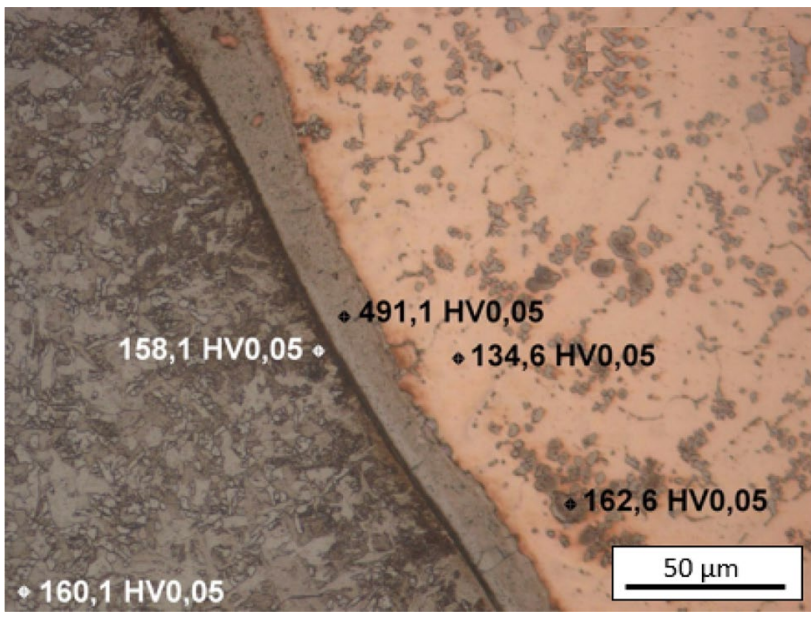

Fig. 18 Hardness HV 0.05 in braze weld of the 10CrMo9-10 steel tube, made using bronze filler metal $\mathrm{CuSi} 3$

Open Access This article is licensed under a Creative Commons Attribution 4.0 International License, which permits use, sharing, adaptation, distribution and reproduction in any medium or format, as long as you give appropriate credit to the original author(s) and the source, provide a link to the Creative Commons licence, and indicate if changes were made. The images or other third party material in this article are included in the article's Creative Commons licence, unless indicated otherwise in a credit line to the material. If material is not included in the article's Creative Commons licence and your intended use is not permitted by statutory regulation or exceeds the permitted use, you will need to obtain permission directly from the copyright holder. To view a copy of this licence, visit http://creativecommons.org/licenses/by/4.0/.

\section{References}

1. Shiri SG, Nazarzadeh M, Sharifitabar M, Afarani MS. Gas tungsten arc welding of CP-copper to 304 stainless steel using different filler materials. Trans Nonferrous Met Soc China. 2012;22:937-2942.

2. Magnabosco I, Ferro P, Bonollo F, Arnberg L. An investigation of fusion zone microstructures in electron beam welding of copper-stainless steel. Mater Sci Eng A. 2006;424:163-73.

3. Kuryntsev SV, Morushkin AE, Kh Gilmutdinoy A. Fiber laser welding of austenitic steel and commercially pure copper butt joint. Opt Lasers Eng. 2017;90:101-9.
4. Sabharwall P, Clark DE, Mizia RE, Glazoff MV, Mckellar MG. Diffusion-welded microchannel heat exchanger for industrial processes. J Therm Sci Eng Appl. 2013. https://doi. org/10.1115/1.4007578.

5. Mirski Z, Granat K, Prasałek A. The diffusive barriers in copper brazing with austenitic steel by use the $\mathrm{Cu}-\mathrm{Ag}-\mathrm{P}$ (L-Ag15P) filler metal. Arch Metall Mater. 2008;53:1035-46.

6. Mirski Z, Granat K, Bulica A. Problems at bonding copper with acid-resistant steel. In: Proceedings of PIRE 2005 Conference. Problemy i inowacje w remontach energetycznych. OBR Gospodarki Remontowej Energetyki. 2005;211-222 (in Polish).

7. Massalski TB. Binary alloys phase diagrams, vol. 1. ASM International: Cleveland; 1992.

8. Lison R. Wege zum Stoffschluss über Schweiss- und Lötprozesse. Düsseldorf: DVS; 1998.

9. Mirski Z, Granat K, Winiowski A, Bulica A. Comparison of methods of bonding copper with austenitic steel. Inżynieria Materiałowa. 2006;3:205-8 (in Polish).

10. Pfeifer T, Stano S. Modern methods of braze welding from the viewpoint of quality and properties of joints. Weld Technol Rev. 2016;9:95-102 (in Polish).

11. Mirski Z, Wojdat T, Margielewska A. Braze welding of dissimilar materials. Inst Weld Bull. 2018;3:26-322 (in Polish).

12. Goecke SF. Low energy arc joining process for materials sensitive to heat. Mater EWM Hightec Weld. 2005;11:1-5.

13. Matusiak J, Czworonóg B. Low-energy processes of arc welding under gas shielding for joining thin steel sheets. HutnikWiadomości Hutnicze. 2008;1:10-6 (in Polish).

14. Mirski Z, Wojdat T, Kustroń P, Dreko W, Mroczkowski L, Lądyszkowska D. Robotized CMT arc braze welding of $\mathrm{Cu}$-lined 10CrMo9-10 steel tube. Inst Weld Bull. 2018;5:33-9 (in Polish).

15. Bruckner J, Wagner J, Arenholz E. The CMT - process - a revolution in welding technology. Int Light Metals Technol Conf. 2005;2:275-81.

16. Wojdat T, Kustroń P, Skuratowicz F, Michalak P, Piotrowska P. Application of low-energy CMT process for braze welding of copper with acid resistant steel under various gas shieldings. Weld Technol Rev. 2018;1:15-20 (in Polish).

17. Kubaschewski O. Iron-binary phase diagrams. Berlin: Springer; 1982.

18. González F, Houbaert Y. A review of ordering phenomena in ironsilicon alloys. Revista de Metallurgia. 2013;49(3):178-99.

19. Zhao J, Zhang L, Du Y, Xu H, Liang J, Huang B. Experimental investigation and thermodynamic reassessment of the $\mathrm{Cu}-\mathrm{Fe}-\mathrm{Si}$ system. Metall Mater Trans A. 2009;40A:1811-25.

Publisher's Note Springer Nature remains neutral with regard to jurisdictional claims in published maps and institutional affiliations. 